\title{
Entre la Revolución Rusa y Nuestra América. La prensa militante: 1919-1935
}

\author{
Ricardo Melgar Bao
}

INAH-México

melgarr@gmail.com

A Hilda Tísoc Lindley in memoriam, compañera de búsquedas $y$ hallazgos hemerográficos

\section{Primer umbral: hacia una genealogia de la prensa escarlata}

La prensa de las izquierdas, aunque tuvo sus primeras manifestaciones en el siglo XIX, su desarrollo nos remite al siglo XX. Y la prensa cominternista al arco temporal que marcó la existencia de la Internacional Comunista. Representó en muchos sentidos la fuerza expansiva de la Revolución Rusa y del nuevo Estado. Para su mejor comprensión sugerimos ubicarla como un capítulo del devenir de la prensa obrera y de izquierda, ya que reprodujo o retomó elementos previos. Fue así que asumió varias funciones que ya eran familiares a los editores y lectores, aunque con diferenciados énfasis que guiaban sus tareas de educar -o "ilustrar"- a los trabajadores; tejer redes de solidaridad local, regional, nacional y, a veces, internacional. Habría que agregar que sirvió de vehículo de denuncia y combate contra las fuerzas sociales e ideológicas y sus dirigentes o epígonos, a las que consideraban adversarios o enemigos.

Algunos analistas sostienen equívocamente que la prensa cominternista se explica por sí misma, obviando la existencia de tradiciones previas, que habian modelado los modos de escribir y leer. Recordemos que los impresores ya habian aprendido a aceptar los riesgos de edición (periódicos, carteles, folletos, libros), que podian levantar las iras gubernamentales. En 1901 Luis Emilio Recabarren (1876-1924), la figura mayor del socialismo chileno, expresó con claridad la función política, educativa y cultural de la prensa obrera para su país. Una línea de continuidad en su pensamiento acerca del diarismo atraviesa su militancia democrática, socialista y comunista. Pensando en térmi- 
nos más amplios consideramos que sus primeras palabras al respecto tradujeron también la orientación hegemónica de la prensa obrera y de izquierda en el continente, salvo su criterio utopista de confiar en su capacidad de convencimiento hacia quienes extraviaron el camino, o de quienes se convirtieron en oponentes y que en no pocos momentos lo hostigaron policialmente y censuraron la prensa obrera y socialista:

La prensa obrera tiene por misión sagrada contribuir a la ilustración y difundir la cultura en las costumbres de los pueblos.

Un periódico que llegue a las manos de un hijo del trabajo debe ser un libro en el cual encuentre la savia vivificante para fortalecer el espíritu, cuando abatido por las luchas de la vida, se siente adormecer. [...]

Debe rebatir las ideas del adversario o del amigo, cuando no las creas buenas, con cultura, moderación y altura de miras, procurando convencer al que se crea en marcha extraviado con buenas razones y con argumentos... ${ }^{1}$

La prensa obrera no es sinónimo de prensa de izquierda, tampoco lo es la prensa sindical. La primera no implica necesariamente a las otras. Sin embargo, entre ellas hubo mixturas, mediaciones y más de algún desencuentro. La prensa cominternista tendió a abrirse como un abanico, teniendo como columna vertebral a la partidaria y como subalternas a las dirigidas a sectores obreros sindicalizados, a los intelectuales, a la juventud y ocasionalmente a los campesinos, jornaleros rurales o indígenas.

La prensa de izquierda fue significada en primer lugar por su carácter combativo en los terrenos ideológicos y políticos, exponiendo su punto de vista acerca de ciertos hechos o acontecimientos afines a los intereses de sus agrupaciones y de las clases subalternas. En segundo término, por ser un vehículo de transmisión de ideas $\mathrm{y}$, por ende, de construcción de identidad política. En tercer lugar, por cumplir una función pedagógica.

Podemos afirmar que en sus inicios y en la mayoría de nuestros países, la prensa cominternista fue laxa, al punto que bien podriamos filiarla como filocominternista. Careció de un centro. Expresó, más bien, las ideas y acciones de algunos núcleos comunistas obreros, intelectuales o mixtos. La simultaneidad de sus expresiones gráficas aunadas a las debilidades orgánicas de las organizaciones procominternistas permitieron apreciar la existencia de autonomías relativas por parte de sus editores locales, las cuales incidieron en sus públicos lectores.

1. Luis E. Recabarren, "El deber de la prensa obrera" (1901), en Cruzat y Devés (2015). 
Fueron tiempos en que el imaginario social de las clases subalternas, principalmente urbanas de la primera posguerra, sintió el influjo de la Revolución Rusa, gracias a la prensa militante. Sin embargo, debe ser ubicada en un proceso mayor que la vinculó a la guerra civil y a la constitución del Estado socialista, entre el comunismo de guerra y la Nueva Política Económica. Así las cosas, la recepción continental de dicho proceso permitió encontrar vías muy sugerentes acerca de la diversidad étnica y religiosa, el comunalismo rural (el mir) y la construcción de un Estado más inclusivo e internacionalista.

Durante esos años las organizaciones sindicales y politicas vivieron un proceso de escisión y remodelación cultural en el cual cumplió un papel de primer orden la prensa de la Internacional Comunista (IC). Las ideas, los lemas, los símbolos y los temas iconográficos se volvieron familiares, afines, transfronterizos. Se sumó a lo anterior la presencia de influyentes cuadros itinerantes, los que destacaron temporalmente en algunos países latinoamericanos y que eran portadores de la línea a seguir y de experiencias gráficas europeas. Coadyuvó a lo anterior el envío de dirigentes a Moscú y su incorporación a las escuelas de capacitación política de la IC. Era la primera vez que una Internacional pretendia echar raices de modo profundo fuera de Europa y en buena medida lo hizo a través de su prensa, la cual logró cierta autonomía cribando particularismos editoriales y de contenido político-cultural no previstos en Nuestra América. José Carlos Mariátegui no se equivocó cuando afirmó que la III Internacional, a diferencia de las precedentes, mucho más que europea, en cierto sentido fue ecuménica.

Afirmamos que el camino de la nueva Internacional fue sinuoso. Sus origenes nos indican que sus dirigentes tenian muchas dudas sobre su carácter y su horizonte de futuro en los continentes periféricos. La carta de invitación al Congreso Constituyente de la IC, redactada por Trotsky y suscrita por ocho organizaciones partidarias en enero de 1919, entre ellas el Socialist Labor Party de los Estados Unidos, tradujo una concepción orgánica bastante amplia sobre la composición politica de los asistentes a su congreso fundacional. Este documento hizo extensiva la invitación a las corrientes no comunistas del sindicalismo revolucionario de la IWW de los Estados Unidos, Inglaterra y Australia, así como a las filiadas como socialistas en los países escandinavos.

Aunque para el núcleo organizador cominternista el centro seguía siendo Europa, en sus análisis y consideraciones táctico-estratégicas sobre la revolución, la lucha contra la II Internacional y la conquista del movimiento obrero, la participación del mundo colonial (Irlanda), los países orientales (Turquía, Persia, China, Turquestán, Georgia, Azerbaiyán, etc.), asi como la participación de los llamados países campesinos de los Balcanes, forzaron una situación nueva. Su sola participación 
simbolizaba de manera evidente la impugnación del horizonte obrerista y europeísta con que se proyectó el nacimiento de la III Internacional. Si bien es cierto que América Latina quedó ausente de la agenda en sus inicios, no tardaron en manifestarse las primeras adhesiones y formas orgánicas pro cominternistas en países como Argentina, Brasil, Chile, México y Uruguay.

La orientación general del evento comunista tuvo como rasgo sustantivo la necesidad de diferenciarse de la II Internacional y obtener un perfil propio en lo ideológico, teórico, político y orgánico. La crítica al neokantismo, evolucionismo y machismo como corrientes ajenas al marxismo se presentaba como un elemento de necesaria convergencia ideológica para oponerse y criticar a las bases doctrinarias del socialismo, sindicalismo y cooperativismo reformista. El repudio al colaboracionismo socialista, tanto al guerrerismo burgués de la Primera Guerra Mundial, como a la política colonial propia de la nueva fase de crisis capitalista, fue otro rasgo sustantivo de la izquierda cominternista. Los términos socialcolonialismo, socialimperialismo y socialtraidores evidenciaban la pasión por la crítica, la lucha por su propia identidad y la pérdida de su capacidad de convocatoria. En general, su prensa, sus símbolos, sus formas orgánicas y sus tácticas de lucha fueron modelando una subcultura política. Destacaba su reivindicación de la violencia revolucionaria, significada por la acción directa de las masas bajo la pretensión de conquistar el poder y sentar las bases de una nueva sociedad. Su énfasis puesto en los consejos de fábrica, el sindicalismo revolucionario, los comités de acción sindical, así como en el partido de tipo conspirativo, expresaron en lo orgánico un rechazo y negación del legado reformista de la II Internacional, pero también del radicalismo espontaneísta de la I Internacional. La Revolución socialista fue su norte principal, al que estaba asociado, su apuesta a favor de la reorientación revolucionaria de los movimientos anticolonialistas y antiimperialistas.

En Moscú, durante el I Congreso de la IC en marzo de 1919, tomando como base la invitación al mismo, el espartaquista Hugo Eberlein (Albert) y el bolchevique Nicolai Bujarin se abocaron a redactar su plataforma, con la finalidad de trazar los lineamientos políticos y programáticos de la praxis comunista mundial. Su contenido se dividió en cuatro puntos: conquista del poder político; cuestión de la democracia o la dictadura de clase; expropiación de la burguesía; y construcción del estado proletario y el camino de la victoria. De ellos se desprendieron los objetivos de destrucción del aparato estatal construcción del estado proletario; la defensa de la dictadura del proletariado frente al acoso reaccionario; la vigencia de los soviets o consejos como órganos de la democracia socialista; la confiscación y socialización de fábricas, latifundios, bancos, comercios y servicios en oposición al gradualismo estatista de los 
reformistas; la práctica de "la acción directa de las masas incluido su resultado lógico, el choque directo, la guerra declarada con la máquina de estado burguesa" en rechazo al pacifismo y oposición tolerada de la II Internacional (Castro, 1975).

En 1921, en las páginas de La Internacional, vocero de los comunistas argentinos, se publicaron las primeras crónicas de viaje a Rusia de Rodolfo Ghioldi. ${ }^{2}$ No fue el único viajero, pensemos en las crónicas publicadas por Luis Emilio Recabarren. ${ }^{3}$

Concluido el periodo 1919-1923, tiempo de formación de sus primeras secciones en el continente y de la aparición de sus aurorales periódicos, constatamos que en el curso de los siguientes diez años continuó la extensión del movimiento comunista organizado, llegando a abarcar la región andina y el Caribe. Hemos de destacar que fue acompañado de procesos de escisión que dieron origen a partidos como el que fundase José F. Penelón en Argentina, o las diversas entidades filiadas como parte de la "Oposición Comunista", pero también de autonomización, como sucedió con el movimiento socialista liderado por José Carlos Mariátegui en el Perú (Camarero, 2007; Flores Galindo, 1980). Esta historia dejó huella en sus periódicos y revistas, cominternistas o no.

Entre los años 1919 y 1923, el tópico de la Revolución Rusa se había expandido de muchos modos en el imaginario social latinoamericano; no así los enfoques antiimperialistas, todavía demasiado deudores del arielismo rodoniano. Se había transitado de las noticias difusas o sesgadas acerca del proceso revolucionario ruso a la recepción de los primeros textos político-doctrinarios elaborados dentro o fuera de sus fronteras. Corrian los tiempos de lucha por la difusión del marxismo cominternista en América Latina. Los contados artículos del principal vocero cominternista sobre la región expresaban un cierto desinterés por el fenómeno imperialista, acaso porque todavía se creía que la fase de ascenso revolucionario en Europa cambiaria su faz, su orden, su futuro. ${ }^{4}$ De manera gradual y convergente con la atención que suscitaba la Revolución China y la fase de reflujo revolucionario europeo, la

2. R. Ghioldi, "El viaje. Carta desde Moscú", en La Internacional (Buenos Aires), 15 de agosto de 1921; R. Ghioldi, "Un sábado comunista de los delegados extranjeros", en La Internacional (Buenos Aires), 9 de octubre de 1921.

3. Luis E. Recabarren, "Desde Moscú: Organización fundamental de las industrias", La Federación Obrera (Santiago), 3 de febrero de 1923; "En Moscú: Una pequeña velada por el grupo hispano-sudamericano”, La Federación Obrera (Santiago), 4 de febrero de 1923.

4. Según se desprende de la consulta de los ejemplares existentes de la edición francesa de La Correspondance Internationale entre los años 1921 y 1923 en la Biblioteca del Instituto Internacional de Historia Social de Ámsterdam y la Biblioteca Nacional de París. 
cuestión antimperialista se fue haciendo visible. Los escritos de Lenin comenzaron a ser traducidos y publicados en los periódicos comunistas ${ }^{5}$ o bajo la forma de folletos. ${ }^{6}$ Fue acaso excepcional la edición castellana en México, en 1922, de una de las primeras reinterpretaciones titulada El imperialismo americano, de Luis C. Fraina. ${ }^{7}$

En la siguiente fase de entreguerras, se vivió la lucha por la asimilación y desarrollo creador del marxismo latinoamericano, el cual iba en contra de las versiones europeístas y orientalistas. ${ }^{8}$ Ése fue el período de constitución de las ligas antiimperialistas y de otras organizaciones disidentes y alternativas de filiación socialista, como la Unión Latino Americana (ULA) o la Unión Centro Sudamericana y de las Antillas (UCSAYA) y la más vernácula y populista de la Alianza Popular Revolucionaria Americana (APRA). ${ }^{9}$ Por esos años comenzaron a proliferar las lecturas y estudios sobre el fenómeno imperialista en América Latina, los que pueden ser rastreados a través de la prensa cominternista de cada país.

5. Véase Vladimir Ilich Lenin, "Mensaje a los soviets húngaros", Documentos del Progreso (Buenos Aires), año 1, n 2, 15 de agosto de 1919, y "Una nueva carta a los trabajadores de Europa y Norte América”, Documentos del Progreso (Buenos Aires), año $1, n^{\circ} 3,1$ de septiembre de 1919 .

6. Vladimir Ilich Lenin, El imperialismo, fase superior del capitalismo, Santiago de Chile: Nueva América, 1917.

7. La relevancia es mayor si consideramos que el texto de Lenin incluido por dicha biblioteca fue El Estado y la revolución (1921), que la editorial cominternista La Internacional de Buenos Aires editó en 1922, pero ninguno dedicado al tema del imperialismo.

8. Entre los primeros artículos sobre el tema del imperialismo en América Latina destacan George Harrison, "Les intrigues des Etats Unis aux Nicaragua", La Correspondance Internationale, 12 de enero de 1925, p. 75; J. Wilenklin, "Au Mexique. La Lutte du gouvernement et des ouvriers contre l'Église catholique et l'impérialisme Américain", La Correspondance Internationale, $\mathrm{n}^{\circ} 128,28$ de noviembre de 1926, p. 1558; "L'Affaire de Tacna-Arica et l'impérialisme Américain", La Correspondance Internationale, $\mathrm{n}^{\circ} 32,13$ de mayo de 1926, p. 288. A partir de 1927 la atención sobre el fenómeno imperialista y la propia región se despuntó con siete artículos, dos sobre la región en su conjunto escritos respectivamente por el propio Comité Ejecutivo y un tal M. Tanin; los restantes refieren los casos de México y Nicaragua, uno de ellos redactado por Codovilla. Entre 1928 y 1929, el vocero cominternista sólo dedicó un artículo específico a la agresión imperialista rubricado por el venezolano Salvador de la Plaza, "La lutte du Nicaragua, lutte de l'Amérique Latine pour son indépendance", La Correspondance Internationale, $\mathrm{n}^{\circ}$ 9, 28 de enero de 1928, p. 119, y en los demás artículos el imperialismo aparece como un referente obligado y de cliché en los análisis esquemáticos sobre la reacción y el terror de las clases opresoras en la Argentina, Brasil, Uruguay, salvo en algunas de las reproducciones de las intervenciones de los delegados latinoamericanos en el curso del VI Congreso de la IC (1928).

9. Véase Melgar Bao (2006-2007, 2010 y 2002). 
El tenor conmemorativo del centenario de la independencia en varios países de la región reavivó entre la intelectualidad democrática y de izquierda el celo por la soberanía frente al creciente injerencismo norteamericano, suscitando nuevas lecturas de Martí y de Bolivar. Y fue evidente que el perfil de uno y otro proceso, así como de las necesarias y diversas mediaciones del primero al segundo periodo, no tuvo el mismo rango de dificultad teórica y complejidad real. Una exhaustiva cronología sobre las intervenciones imperiales en América Latina debida a Gregorio Selser nos permite subrayar la existencia de un punto de viraje gracias a la resistencia de Sandino y su pueblo frente a la ocupación norteamericana de Nicaragua (Selser, 2001: 377-572), la cual impactó a la propia Internacional Comunista en su lectura regional.

Recuérdese que entre 1924 y 1925 aparecieron las versiones principales del "leninismo", según lo refrendó la aparición de los polémicos ensayos sobre el tema elaborados por Zinoviev, Bujarin, Trotsky y Stalin. Fue así que la obra de Lenin quedó filtrada por estas versiones, deudoras de sus deficientes y escasas traducciones en América Latina. De este modo, la tesis sobre el imperialismo como fase superior del capitalismo devino en "fase final". En lo general, desde el mirador cominternista posleninista se comenzaron a reconfigurar los conceptos de revolución, partido, imperialismo y antiimperialismo, consideradas como las claves de un disputado legado leninista. La gesta sandinista generó muchas versiones, tantas como facciones cominternistas existian, en cuyas discrepancias afloraba un lenguaje común: partido, revolución, clase, imperialismo. La misma tónica apareció en las lecturas de otros procesos nacionales de interés cominternista.

Entre los años 1924 y 1929, a la IC le tocó vivir una de sus fases de mayor trascendencia y crisis politica. Fallecido Lenin, las facciones del PCUS exacerbaron sus contradicciones al punto de afectar la orientación de la propia Internacional. El eje de sus disputas pasaba por la mediación legitimadora del "legado leninista" de la Revolución de Octubre: la construcción del socialismo en un solo país y el curso de la Revolución mundial. Desde el mirador cominternista latinoamericano, hubo amalgama de ideas y dudas antes que debates y fracturas sensibles. La campaña antitrotskista sembró más fantasmas e incomprensiones acerca de sus propias divergencias sobre los asuntos capitales de la cuestión nacional o continental.

El segundo ciclo de la IC se caracterizó por una aguda beligerancia ideológica, en el marco de un período de relativa estabilización capitalista y de asentamiento de la economía soviética, previa a la crisis de 1929. El faccionalismo político cominternista y su desarrollo orgánico, partidario y sindical, contrastaba con una fase de reflujo del movimiento revolucionario en el escenario mundial. Este particularismo se hizo 
evidente en nuestra región, expresándose en la búsqueda del carácter de la revolución latinoamericana más allá de las tesis europeístas y orientalistas. Así, el problema del imperialismo parecía abarcarlo todo, pero el modo de leerlo y atenderlo políticamente carecía de consenso. Fue altamente significativo que el mejor estudio sobre el imperialismo norteamericano desde el ángulo económico fuese publicado en Nueva York a mediados de 1925 por dos profesores norteamericanos, Scott Nearing y Joseph Freeman su obra fue traducida al castellano y editada en México, ${ }^{10}$ convirtiéndose en un clásico para los cuadros cominternistas latinoamericanos. No fue casual que la prensa militante reprodujese varios pasajes de dicha obra.

Durante este mismo período, la dispersión y confrontación faccional aproximó las vanguardias latinoamericanas más a la corriente bujarinista que a la trotskista, zinovietista o estalinista. Frente a la versión trotskista sobre la Senda de Occidente, el camino de Oriente promocionado por Zinoviev a pesar suyo, y más propiamente por las corrientes estalinista y bujarinista, logró consolidar una precaria hegemonía en el seno de la IC. Un sector de los cominternistas latinoamericanos celebró el reconocimiento de la vía oriental, pero marcó sus distancias en la medida en que no consideraron a sus países como colonias, por lo que les tocaba vivir otra etapa. ${ }^{11}$

El eclecticismo y la flexibilidad tanto de las tesis orientalistas suigeneris del estalinista ruso Gusev como de las del bujarinista Humbert-Droz representaron un interesante esfuerzo de réplica a las impugnaciones del paradigma europeísta de la revolución mundial por parte del sector más crítico de la vanguardia comunista de América Latina. Próximos a éstos, sostenian que la lucha antiimperialista y antiburguesa era posible, además de que acortaba los caminos y tiempos hacia el socialismo.

10. Scott Nearing y Joseph Freeman, La diplomacia del dólar: un estudio acerca del imperialismo americano, México, Sociedad de Edición y Librería Franco-Americana, 1926.

11. La postura de Mariátegui el 28 de septiembre de 1923 fue muy clara y concisa sobre la nueva coyuntura mundial: "Esta situación nueva se puede resumir en tres observaciones: 1) Europa carece de autoridad material para sojuzgar a los pueblos coloniales, 2) Europa ha perdido su antigua autoridad moral sobre esos pueblos; 3) La conciencia moral de las naciones europeas no consiente en esta época, al régimen capitalista, una politica brutalmente opresora y conquistadora contra el Oriente. Existen, en otras palabras, las condiciones históricas, los elementos políticos necesarios para que el Oriente resurja, para que el Oriente se independice, para que el Oriente se libere. Así como, a principios del siglo pasado, los pueblos de América se independizaron del dominio político de Europa, porque la situación del mundo era propicia, era oportuna para su liberación, asi ahora los pueblos del Oriente se sacudirán también del dominio político de Europa, porque la situación del mundo es propicia, es oportuna para su liberación" (1994: 899-902). 
Desde otro mirador, la URSS, a diferencia del período anterior, se veía obligada a inaugurar una nueva política internacional, diplomática y comercial frente al cerco imperialista europeo y norteamericano. Los intereses del Estado soviético afectaron, y fueron afectados a su vez, por la labor revolucionaria de la IC, lo cual se manifestó en América Latina. Los casos de México y Argentina fueron ilustrativos, tanto por el asunto del petróleo como por el de la minería y la ganadería. Sin embargo, sería erróneo e injusto afirmar que las secciones adheridas a la IC, reconocidas o no, fueron marionetas de la politica soviética del "Socialismo en un sólo País". Por el contrario, floreció la defensa de la relativa autonomía de los partidos socialistas revolucionarios vinculados a la IC en Bolivia, Colombia, Ecuador, Perú y Venezuela, cuando menos hasta los inicios de 1930. Las páginas de El Libertador-el vocero de la Liga Antiimperialista de las Américas-, y aún de La Correspondencia Sudamericana-vocero del secretariado Sud Americano de la IC-, así lo refrendan.

La propia Liga Antiimperialista Mundial mantenía una autonomía y flexibilidad que no ostentaba, para los mismos años, la Internacional Sindical Roja (ISR), aunque sí la Internacional Campesina (Krestintern), la cual tenía como figura mayor en la región al mexicano Úrsulo Galván y alguna otra. La Liga Antiimperialista de las Américas tenía, desde su fundación en 1925, su sede principal en México, pero a partir de febrero de 1927 la sección argentina pugnó por lograr la hegemonía estaliniana en su seno, bajo el liderazgo de Codovilla. Al mismo tiempo, la flexibilidad politica de la Liga fue puesta a prueba con motivo de la disidencia aprista liderada por Haya de la Torre en el curso del Primer Congreso Antiimperialista Mundial, realizado en Bruselas en 1927.

Al respecto, mención especial merece la participación cubana dentro y fuera de la isla a través de las figuras señeras de Rubén Martínez Villena y Julio Antonio Mella. Martínez Villena, desde la dirección de la revista Venezuela Libre (1925), y principalmente desde América Libre (1927), ${ }^{12}$

12. Venezuela Libre (La Habana) se adscribió en su segunda época como "órgano revolucionario latinoamericano" e hizo explícito un claro tenor antiimperialista, como apareció en su edición especial números 14 al 18 (septiembre-diciembre de 1925). En la portada definió su postura con tres lemas ubicados en su campo izquierdo de arriba a abajo: Por la libertad de los Pueblos, Contra las tiranías de América, Contra el Imperialismo yanqui. En su campo derecho una imagen simbólica, en ella y encerrada en un círculo apareció la figura cartográfica de las dos Américas oprimidas por una serpiente enroscada en torno suyo, cuyas fauces estaban proyectadas sobre la isla de Cuba, El artículo central fue el de Julio Antonio Mella, titulado "Hacia una Internacional Americana" acompañado de varios textos antiimperialistas. Una nota refería que la Liga Antiimperialista de las Américas contaba con tres secciones: la norteamericana de Manuel Gómez, la mexicana de Rafael Carrillo y la de Cuba de Julio A. Mella. Por su parte, América Libre, se adscribió como Revista Revolucionaria Americana desde su primer número en abril de 1927. Entre sus redactores estaban 
promovió las primeras campañas antiimperialistas de la Liga, mientras que Mella, desde su exilio en México, capitalizó las diversas tribunas periodísticas o de plaza pública a su alcance. Su obra más conocida es el deslinde que realiza frente a Haya de la Torre y el APRA, ¿Qué es el Arpa? La lucha revolucionaria contra el Imperialismo (México, 1928).

A pesar de ello, el legado de los congresos precedentes en política campesina, sindical, intelectual y antiimperialista, asimilado por los comunistas latinoamericanos, no pudo ser cancelado por la línea izquierdizante del VI Congreso de la IC de "clase contra clase" (1928). En este sentido, el período 1924-1929 representó, desde la perspectiva de sus luchas internas, la continuidad y la persistencia de las tesis clasistas $\mathrm{y}$ frentistas del período precedente.

\section{Segundo umbral: proceso, estigma y realidad}

Durante esos años, que pueden ser considerados formativos, los trabajadores y los militantes de izquierda tuvieron conductas diferenciadas frente a un periódico o una revista de orientación revolucionaria o reformista. Al mismo tiempo, se orientaron a contracorriente del estigma que pesaba sobre los comunistas, el cual era difundido por los grandes diarios burgueses. Aprendieron a ponderar que las formas materiales de los medios gráficos obreros o de izquierda, además de ser vehículos de información o cultura accesibles a sus magras economías, les podian ocasionar riesgos de seguridad en el empleo o en la vida pública. Leer o escuchar la lectura de los titulares y contenidos de dichos medios gráficos fueron prácticas inherentes de su consumo popular. La lectura en voz alta de los titulares y artículos de los periódicos en el seno de un círculo, comité o célula, remontaron a contracorriente los saldos de exclusión social de los servicios de educación pública. La mayoría de las veces, los editores prescindian de remitir un ejemplar de cada edición a las bibliotecas públicas. Las colecciones de periódicos y revistas revolucionarias existentes en locales sindicales, politicos y culturales

los exiliados peruanos Esteban Pavletich y Luis F. Bustamante, quienes poco después serían deportados de la isla, al igual que el venezolano Gustavo Machado. En el número 2, de mayo de 1927, Bustamante escribió un importante texto que aproximó al Congreso de Bruselas con la reunión o Conferencia de Colonia promovida por Haya de la Torre días más tarde de cumplida su ruptura con Mella, titulado "Dos Congresos Anti-Imperialistas". La cabida que le dio Martínez Villena al artículo de Bustamante consideramos que únicamente señala la dificultad de posicionarse en ese momento político frente a un deslinde cuyos términos recién serian conocidos más tarde. Lo ratifica el hecho de que la revista publica una nota aclaratoria en su $n^{\circ} 4$, de julio de 1927, y el hecho de que el propio Bustamante rompiese poco después con Haya de la Torre. 
fueron muchas veces motivo de requisa policial o militar. Muchos militantes, activistas o dirigentes que fueron poseedores de dichos acervos han testimoniado su pérdida, sea por acción de un allanamiento a sus moradas, descarte por mudanza, motivo de seguridad, o falta de previsión de medios adecuados para preservarlos.

La prensa cominternista, durante el período de entreguerras, se afirmó como una prensa de carácter faccional con no pocas mudanzas de linea editorial. Fue faccional con respecto al abanico de publicaciones eventuales, periódicas o semiperiódicas generadas por otras corrientes de la izquierda continental y mundial, con las cuales muy ocasionalmente practicaba algún eventual acercamiento y canje. Desde otro ángulo, se inscribió en la misma tradición de la prensa obrera y de izquierda, iniciada durante la segunda mitad del siglo XIX, que fungió como el principal medio letrado formador de cultura politica de las clases subalternas urbanas. La mayoría de sus emprendimientos resintió tanto la censura gubernamental como sus limitaciones económicas.

Recabarren, con motivo de su viaje a Moscú para asistir al IV Congreso de la Internacional Comunista en 1922, describió la nave central del palacio zarista expropiado por los bolcheviques y entregado al Comintern. En su pared figuraba la simbólica unidad de las prensas de todas las secciones nacionales:

Un tablero muy grande tiene dibujada una estrella de muchos picos y en cada uno de ellos se ha pegado el recorte o la cabeza o título de cada uno de los periódicos y diarios comunistas del mundo, indicando su nacionalidad. ${ }^{13}$

No podía encontrarse en dicho mural gráfico el vocero del Partido Comunista de Chile, ya que no existía como tal. El dirigente chileno había colaborado, sea en la fundación o como articulista en las páginas de algunos periódicos filocominternistas como: La Chispa comunista de Talcahuano, La Comuna de Viña del Mar y El Comunista de Antofagasta. Cerró su ciclo periodístico con doce colaboraciones publicadas entre el 20 de febrero y el 15 de noviembre de 1924 en las páginas de Justicia, 34 días antes de su suicidio. Su última nota periodística en coautoría con Luis V. Cruz fue un mensaje de admonición dirigido a la clase obrera y a los militantes, a poco más de un mes de su suicidio un 19 de diciembre del mismo año: "Dependerá de que ustedes y nosotros lleguemos a hacer de este diario Justicia una poderosísima palanca intelectual que

13. Luis Emilio Recabarren (20 de marzo de 1923), "En Moscú: Los dos Congresos Internacionales: El Comunista y El Sindical Rojo". 
mueva la opinión nacional a favor del programa de mejoramiento que nos es común" (Massardo, 2008: 307-308; Cruzat y Devés, 2015: 769).

El caso mexicano ilustra algo respecto de los orígenes. En dicho país se publicaron, en 1919, El Soviet (octubre) bajo la dirección de Eduardo Camacho, El Comunista (diciembre de 1919) dirigido por Elena Torres. En 1920: Juventud Mundial (julio) a cargo de José Valadés, El Comunista de México (julio) bajo la animación de Linn E. Gale, Vida Nueva (agosto) bajo el liderazgo de Manuel Díaz Ramírez, Boletin Comunista inicialmente a cargo de Manuel Díaz Ramírez, Alba Roja dirigida por Francisco Vela y El Trabajador como vocero de la sección mexicana de la ISR. En 1921: El Comunista de México bajo la orientación de Louis Fraina (pseudónimo Luis Carlos Fernández), El Obrero Comunista y Rebeldia. Todos ellos precedieron a El Machete, primer órgano central y, por ende, nacional del PCM a partir de 1924 (Martínez Verdugo, 1985: 24, 32-33, 408-409; Cruzat y Devés, 2015).

Merece unas líneas la prensa campesina e indígena de izquierda. En primer lugar, la aceptación de que las clases subalternas rurales y las minorias étnicas, debido a sus más acentuadas marcas idiomáticas y ágrafas, tuvieron un proceso de recepción más restringido o accidentado de la prensa. No obstante lo dicho, llegaron a contar con excepcionales proyectos como el de los periódicos mexicanos La Voz del Campesino en Veracruz dirigido por el dirigente campesino Úrsulo Galván, representante de la Krestintern para nuestro continente, ${ }^{14}$ Tahuantinsuyo y Túpac Amaru en el Perú de los años 20 del siglo pasado. Tahuantinsuyo surgió como expresión de un acuerdo del Primer Congreso Indígena de 1920. Hipólito Salazar -conocido dirigente anarco bolchevique- durante la realización de la sesión del 18 de septiembre de su Tercer Congreso, afirmó: "La propaganda periodística es una de las armas a esgrimir contra el gamonalismo y debe ser un rayo de luz para la culturización de los indígenas que avanzarán más en su organización" (Actas, en Kapsoli, 1977: 225). La semana anterior, en compañia de sus camaradas Vilca, Luis Cáceres, Abraham Cervantes y Ezequiel Urviola, presentaron una moción a favor de la adquisición de una imprenta propia que editase su periódico, la cual fue aprobada por unanimidad (Kapsoli, 1977: 225).

14. Úrsulo Galván editó y dirigió La Voz del Campesino en Veracruz a partir de mediados de la década de 1920. En su segundo número se ratificó la concepción comunalista de dicho periódico: "La tierra cultivada en común, rinde mayores beneficios con menos esfuerzos. Si el cultivo en común alcanzase su grado máximo, sería imposible la prosperidad de los ricos industriales agrícolas. Por eso combaten con tanto ahínco el sistema comunal" (Recopilación de las principales leyes expedidas por conducto de la Secretaría de Agricultura y Fomento, periodo de $1^{\circ}$ de diciembre de 1924 á 6 de enero de 1927, México: Imprenta de la Dirección de Estudios Geográficos y Climatológicos, 1927, p. 217). 
Los mencionados son un buen ejemplo del abanico limitado de emprendimientos de prensa campesina e indigena de izquierda que se gestaron en algunos países del continente. A través de las páginas de estos periódicos se pueden rastrear sus peculiares recepciones de la Revolución Rusa y de otras experiencias en curso en nuestro continente y en Asia.

\section{Tercer umbral: la prensa como fuente nutricia o prescindible}

La perspectiva rusa modeló, al ritmo de sus purgas, relevos y virajes, a la prensa cominternista. Persistió el mismo canon de interpretación de la Revolución de 1917, mucho más sólido que sus imágenes acerca de la construcción del Estado socialista. Esta aproximación a la prensa cominternista ha sido acotado y, por ende, arbitrario, al dejar fuera de su alcance la rica heterogeneidad y el arco temporal mayor de la prensa marxista continental, como los años que van de 1936 a la disolución de la Internacional Comunista en 1943. No obstante lo anterior, contribuye a su esclarecimiento. En primer lugar, nos permite apreciar que más allá de los urgidos referentes nacionales cultivados por los editores, columnistas, colaboradores ocasionales y lectores, estaba muy presente una preocupación y un interés por el panorama mundial y continental, sustentados en la adhesión teórica al marxismo y en alguno de los enfoques sobre el fenómeno imperialista. Asimismo, los períodos de alternancia de crisis y estabilidad capitalista, como de los flujos de ascenso y reflujo de los movimientos revolucionarios y anticolonialistas en curso en los diferentes continentes, eran parte del escenario político y de la reflexión.

Tanto la prensa cominternista como la que se movía en sus bordes con autonomía y originalidad -el quincenario Labor y la revista Amauta dirigidos por José Carlos Mariátegui- fueron modeladoras de una nueva cultura en el seno de las izquierdas y, por ende, de otro lenguaje intelectual, político y simbólico. Esto es refrendado, también, de manera prístina por El Machete, a través de las huellas indelebles que le imprimieron en sus páginas los muralistas, el cubano Julio Antonio Mella y muchos otros de sus colaboradores. Estudiar la prensa militante supone algo más que tomar en cuenta el sentido organizador y revolucionario legado por el leninismo, lo que nos permite explorarla como un espacio de sociabilidad, de fraternidad transfronteriza y de estructuración de redes sociales diversas y convergentes como se expresan a través de sus cartas, de sus obituarios y de sus notas o mensajes solidarios.

La prensa cominternista y la que se cribó en sus bordes, incluida la de la Oposición Comunista, debe ser apreciada como una fuente de 
inestimable valor para la investigación histórica complementaria a las brindadas por los Archivos de Moscú. Durante la última década se reiniciaron con nuevos bríos y enfoques los estudios acerca de la Comintern en América Latina, gracias a que los archivos de Moscú, sumados a algunos de tipo policial, se abrieron a consulta. Estas fuentes brindaron nuevas posibilidades a los investigadores, en tiempos en que los lastres ideológicos de la guerra fría parecian haber quedado atrás.

Existe una visión prejuiciada y anacrónica sobre el valor de las fuentes hemerográficas cominternistas. Varios estudiosos las contraponen a las fuentes documentales partidarias y estatales. En ese contexto las fuentes hemerográficas son consideradas equívocamente como secundarias y subalternas frente a las documentales. Sería más acertado ver su complementariedad. El documentalismo no puede ser celebrado acríticamente. Los documentos apócrifos, o su velado sesgo faccional, pueden confundir al investigador durante momentos de lucha interna y viraje.

Una perspectiva crítica frente al formalismo ingenuo y la precaria axiologia de las fuentes de los monocultores del documentalismo o el hemerografismo, invita a nuevos enlaces entre sí, sin olvidar la utilidad y valor de los testimonios situados dentro o fuera de los llamados archivos de la palabra. Pero para tal fin debemos avanzar en el proceso de inventario. Cierto es que las fuentes hemerográficas cominternistas no están exentas de riesgos: distorsiones intencionales o involuntarias, silenciamientos, magnificación de eventos, sucesos o crecimiento orgánico. Pero a pesar de ello, son susceptibles de ser situadas y explicadas en la urdimbre de los procesos políticos vividos.

Las fuentes hemerográficas suelen proyectar un prejuicio ideológico, dada la baja confiabilidad que exhiben tanto los diarios nacionales como los periódicos que en el campo político expresan intereses particulares. A pesar de lo anterior, merecen ser tomados en cuenta. La posición faccional y la ideología ayudan a comprender a los actores en juego durante el período que se pretende estudiar. Además de lo anterior, nos brindan datos sobre la presencia en ciertos frentes de masas, así como sobre sus urgencias, dilemas, preocupaciones y prácticas, más allá de sus exageraciones y silencios.

La prensa cominternista y la que sin serlo se expresó en sus bordes, contiene en sus páginas un valioso universo de manifestaciones discursivas que delinearon los contornos de los posicionamientos de las izquierdas comunistas frente a coyunturas politicas específicas nacionales, continentales y mundiales. Recordemos que los comunistas asumieron compromisos fuertes en función de sus concepciones y prácticas sobre la revolución nacional, siempre la sintieron enlazada a la llamada Revolución mundial y de la construcción socialista en la 
URSS, sea para defenderlas o tomar posturas críticas esgrimidas por las corrientes de la Oposición de izquierda.

Consideramos que el universo hemerográfico exhibe sus propias virtudes, las que a veces nos permiten rastrear en los artículos, de modo explícito, sugerido o en lenguaje esópico, la fundamentación ideológica y política de un nuevo viraje, o por lo menos sus indicios, sus tendencias en ciernes o en desarrollo. También nos permite escudriñar tanto las facciones como las redes existentes a partir de coordenadas discursivas, asistencias e intervenciones en eventos o en reportes de acciones politicas o armadas. Sus obituarios, aún en las lindes de la hagiografia, ilustran aspectos no conocidos tanto de los cuadros, como del martirologio, arista relevante de su imaginario y ritual político.

Si el periódico expresa el punto de vista o los intereses del cuerpo editorial frente a un proceso politico o de lucha social o partidaria en la que está participando, o sobre el cual decide brindar una defensa o un parecer disidente, la descripción de un evento, una carta o una imagen circunstanciada puede ser considerada una fuente primaria. Nos debemos guiar por las siguientes preguntas: ¿qué ha dicho ese periódico o revista sobre la problemática, el evento o la praxis politica o social? ¿Cómo lo han dicho o representado en la coyuntura?

Sería más apropiado evaluar cierta heterogeneidad de la prensa cominternista según sus diseños, los contenidos de sus secciones y editoriales, así como por el sello que le imprimía su cuerpo de redactores, corresponsales y colaboradores eventuales. Y a partir de lo anterior determinar su relevancia como fuente, la cual bien puede ser considerada como complementaria o aleatoria a las fuentes documentales utilizadas por el investigador; incluso en el caso de que los colaboradores del periódico o la revista expresen puntos de vista discrepantes.

Y si de estudiar se trata algún periódico o revista por el interés que reviste para el análisis de redes, no debe descuidarse la indagación sobre la propagación de sus ideas e imágenes-fuerza, su circuito de irradiación, la pérdida o no de su periodicidad, la afectación de su distribución, sin obliterar las variantes de sus modos de recepción. No debemos soslayar que la inmensa mayoría de los autores son varones y un número apreciable de ellos son latinoamericanos, aunque los cuadros extranjeros parecen representar las visiones más oficiales u oficiosas de la Comintern. Excepcionales son las colaboraciones de mujeres cominternistas. Myra Page, la feminista norteamericana, escribió acerca de la reforma agraria mexicana en 1925, país que conocería trece años más tarde. Por su lado, la mexicana Maria del Refugio García en 1929 ofreció su visión sobre la participación de las mujeres en la lucha de clases del país azteca.

Por todo lo anterior, debemos matizar nuestra manera tradicional de 
valorar la utilidad y calidad de las fuentes hemerográficas. Estas últimas exhiben cierta heterogeneidad, la cual se traduce en sus respectivas cualidades informativas. Evitemos la fetichización de las fuentes, en aras de considerar la complementariedad que ellas poseen. Los puntos de vista, las pasiones cotidianas o coyunturales, las imágenes que contienen las revistas y periódicos cominternistas merecen mejor atención y trato por parte de los investigadores. Los tropos de la escritura, la retórica llana o barroca, incendiaria o fría, expresan, desde la forma, muchos signos e indicios relevantes acerca de los personajes, los frentes de masas, las tramas intrapartidarias, las proyecciones revolucionarias, las escisiones y los caminos accidentados de la negociación en el propio seno de la Comintern o con los representantes gubernamentales y otras fuerzas políticas.

\section{Cierre de palabras}

Nos interesa dotar de visibilidad a la hemerografia cominternista, es decir, la generada y dirigida por los organismos internacionales y continentales, por mandato o aval moscovita. La proyección periodística de la Revolución Rusa se entrampó en una contradicción insalvable, entre el internacionalismo cominternista que se nutría de las esperanzas y los esfuerzos revolucionarios de sus secciones y la defensa de la Unión Soviética y luego de la figura de Stalin. De las páginas de sus periódicos y revistas, se multiplicaron los estigmas sobre los cuadros de dirección que fueron destituidos y perseguidos, así como sobre algunas corrientes de la izquierda.

Los periódicos y revistas de las secciones nacionales de la IC en nuestra región han tenido mejor suerte, no todos, pero sí varios de ellos. Un hecho aislado fue la reproducción digital de El Libertador (1925-1929), vocero de la Liga Antiimperialista de las Américas, a mi cargo.

Sostenemos que la prensa militante pretendió fortalecer sus filas entendidas como público propio antes que intentar modelar hacia fuera la opinión de las clases subalternas induciéndolas a ciertas prácticas reformistas o revolucionarias. En todo caso, la diferenciación entre la prensa partidaria y la llamada prensa "gris", por ser controlada por los comunistas sin decirlo, no logró diferenciar sus lenguajes y terminó por complicar sus redes sindicales y políticas, así como sus identidades orgánicas. Ejemplos de esta prensa "gris" fueron el Boletin de la IMA (1928-1930), dedicado a los trabajadores de la enseñanza en América Latina, y El Libertador (1925-1929), vocero de la Liga Antiimperialista de las Américas (LADLA). Redondea el campo de periódicos y revistas analizado el quincenario Labor (1928-1929), animado por José Carlos Mariátegui en el Perú, en pos de rutas de experimentación discursiva, 
gráfica y visual. En general, las tres expresiones constituyen un laboratorio inestimable para estudiar las formas de sensibilidad, sociabilidad y las redes que supieron tejer en el seno de sus diferencias.

La prensa cominternista mexicana, en cambio, ha tenido más continuidad. A la precoz reedición en facsimil de El Machete Ilegal (19291933) en 1975, le siguió Frente a Frente (1933-1938), 19 años después; esfuerzo notable por bregar a contracorriente del desplome editorial sobre tópicos comunistas que acompañó el derrumbe del socialismo real en Europa. En la actualidad, nos encontramos en vísperas de la reedición en DVD de El Machete (1924-1938) y de la publicación digital en línea de La Correspondencia Sudamericana (1926-1930) en www. memoriavermelha.com.

Las colecciones de periódicos cominternistas distan de ser accesibles o completas en las hemerotecas públicas en América Latina, mientras que algunos de los archivos reservados de los partidos comunistas, gradualmente han comenzado a abrirse a la consulta externa. Novedad fue la apertura de los "archivos secretos de Moscú" a partir de 1991, los cuales poseen un valor indiscutible, pero son poco accesibles a los investigadores latinoamericanos por falta de recursos institucionales, con la excepción de los casos de Argentina, ${ }^{15}$ Cuba y México. ${ }^{16}$ A lo anterior se suma la muestra documental sobre Ecuador que puede ser consultada en línea: www.yachana.org, y la que sobre Costa Rica publicase Erik Ching (1998).

El historiador Barry Carr $^{17}$ nos ha hecho notar que, a pesar de estas asimetrias existentes entre los investigadores del sur y del norte, se ha democratizado un poco el acceso a los materiales de la IC, considerando el impacto del proyecto Inkomka y la digitalización de una muestra del material. Resulta ahora que se puede consultar el material fuera de Moscú, como por ejemplo en la Biblioteca del Congreso en Washington. En otros casos, los investigadores pueden consultar colecciones microfilmadas de la documentación de la IC en bibliotecas de la Ciudad de México (INAH), en Buenos Aires (Cedinci) y La Habana (Instituto de Historia). Lo que sabemos acerca de los materiales se lo debemos

15. Fue Emilio Corbiére (1998), quién gracias al apoyo financiero del Congreso rescató una copia en microfilm de los archivos de la Comintern sobre la Argentina, accesibles a toda consulta en fotocopias en el Centro Cultural de la Cooperación, entre otros lugares en la ciudad de Buenos Aires.

16. La historiadora Rina Ortiz Peralta fue la responsable de un proyecto de rescate de una copia en microfilm de los archivos de la Comintern sobre México, inicialmente disponible en la Biblioteca del Instituto Mora. Actualmente, dicho material se encuentra microfilmado en la Biblioteca Manuel Orozco y Berra de la Ciudad de México (Ortiz Peralta, 2008).

17. Comunicación personal, 2013. 
principalmente más a investigadores europeos que a norteamericanos. En la actualidad, dichos fondos comienzan a revelar algunos vacíos de información, parcialmente atribuibles a su traslado de urgencia de Moscú, durante la ofensiva militar nazi en 1942. El principal vacío de información acerca de América Latina en los archivos rusos corresponde a los años de la Segunda Guerra Mundial, previos a la disolución de la Internacional Comunista el 15 de mayo de 1943. En no pocos expedientes figuran, además de los documentos, algunos ejemplares de los periódicos militantes. El principal valor documental de los archivos de Moscú cubre de 1919 a 1936, y posee documentos e impresos.

Complica el análisis de la prensa y de los documentos el uso de seudónimos. En parte es explicable por la vida clandestina que vivian varios de ellos. Es difícil identificar, en Pick, al alemán Wilhelm Pieck, aunque el parecido fonético pueda ser considerado como un indicio. No asi en el caso de Sinai, que indiscutiblemente es Sinani. Andrei Volski, quien en 1929 escribió una nota necrológica a la muerte de Guadalupe Rodríguez en México, es Stanislav Stanislavovich Petkovski. Los firmantes como Gómez, como bien lo han señalado Lazar y Víctor Jeifets, pueden referir a más de una identidad: Vicente Uribe Galdeano o Jorge Abilio Vivó Escoto, aunque quizás ninguno de los dos sea el autor del artículo sobre el Perú de 1932.

La cartografia de la prensa cominternista no puede dejar de reconocer la primacía que tuvo el periódico La Correspondencia Internacional y la revista La Internacional Comunista por encima de las demás publicaciones generadas por sus diversos organismos y secciones. Mención aparte merecen los voceros de los secretariados y burós cominternistas para todo el continente, o para sus dos privilegiadas áreas: Caribe y Sudamérica. La Correspondencia Internacional comenzó a editarse a partir de mayo de 1919 en cuatro idiomas: inglés, alemán, francés y ruso. La versión rusa-Kommunisticheskii Internatsional-inicialmente se editó en la ciudad de Petrogrado y posteriormente a través de diversas casas editoriales de diferentes ciudades de la Unión Soviética bajo el control del partido (Albert, 2011: 113). Poco sabemos de quiénes fueron los distintos responsables de su edición, considerando las luchas y las purgas que se libraron en el seno de la IC. En 1931, Vladimir Kuchumov asumió la responsabilidad de su edición (L. y V. Jeifets y Huber, 2004: 170).

El Socorro Rojo Internacional publicó un periódico del mismo nombre en lengua francesa que contiene valiosa información sobre los cuadros comunistas o líderes sindicales que fueron detenidos, deportados, heridos o muertos de movimientos sociales en el continente entre las décadas de los años 20 y 30 . Es menos conocida la prensa de la Internacional Campesina. Otros proyectos cominternistas fueron dedicados al frente 
de los escritores revolucionarios o de las mujeres, publicaciones periódicas de desigual existencia y valor.

Para los que deseen profundizar en esta problemática los invitamos a leer críticamente nuestra obra sobre la prensa militante, que incluye una guía de los diferentes colaboradores y temas alli presentes (Melgar Bao, 2015). Su elaboración siguió un camino largo, discontinuo y sinuoso durante los años 1978 y 2004, sin más recursos que los personales y sin más ayuda que la brindada por Hilda Tísoc Lindley. Implicó un periplo que contempló bibliotecas mexicanas (CEMOS y la ENAH), argentinas (Cedinci y Universidad Nacional de Córdoba), francesas (Biblioteca Nacional de Paris), italianas (Instituto Antonio Gramsci) y holandesas (Instituto Internacional de Historia Social), además de muchas otras públicas y privadas, en las que se encontraron ejemplares aislados y faltantes, todos ellos útiles a nuestros propósitos. Razones ajenas a nuestra voluntad nos impidieron consultar el valioso acervo de la Bibliothèque de Documentation Internationale Contemporaine (BDIC) de Nanterre, entre otros. Por último, cabe señalar nuestra propia adquisición de ejemplares sueltos de publicaciones cominternistas en librerías de viejo en cinco países latinoamericanos: Chile, Costa Rica, México, Perú y Uruguay.

Sin duda, no hemos podido alcanzar un mapeo exhaustivo. Se trata más bien de una cartografia en desarrollo que demanda en perspectiva nuevos esfuerzos, recursos y acción colectiva. Con todo, creemos que, a pesar de sus limitaciones, puede ser útil a los investigadores interesados en la problemática cominternista o en asuntos vinculados a ella. Mucho trecho falta por recorrer en torno a dicha hemerografia: hallar y hacer de dominio público algunas colecciones y abrir un debate al respecto.

\section{Bibliografia}

Albert, Gleb, J. (2011), "Think Tank, Publisher, Symbol: The Comintern in the Early Soviet Media Landscape", The International Newsletter of Communist Studies, XVII, n ${ }^{\circ} 24$.

Camarero, Hernán (2007), A la conquista de la clase obrera: los comunistas y el mundo del trabajo en la Argentina, 1920-1935, Buenos Aires: Siglo XXI.

Castro, Carlos (comp.) (1975), Primer Congreso de la Internacional Comunista, México, Grijalbo.

Ching, Erik (1998), "El Partido Comunista de Costa Rica, 1931-1935: los documentos del archivo ruso del Comintern", Revista de Historia (San José), no 37 , enero-junio, pp. 7-226.

Corbiére, Emilio J. (1998), "Los archivos secretos del PC argentino. La Internacional Comunista en la Argentina (1919-1943)", Todo es Historia (Buenos Aires), año XXXII, nº 372, julio, pp. 12-19. 
Cruzat, Ximena y Eduardo Devés (comps.) (2015), Luis Emilio Recabarren. Escritos de prensa, 1898-1924, Santiago de Chile: Ariadna Ediciones.

Flores Galindo, Alberto (1980), La agonía de Mariátegui: la polémica con la Komintern, Lima: DESCO.

Jeifets, Lazar, Victor Jeifets y Peter Huber (2004), La Internacional comunista y América Latina, 1919-1943: Diccionario biográfico, Moscú: Instituto de Latinoamérica de la Academia de las Ciencia; Ginebra: Institut pour l'Histoire du Communisme.

Kapsoli, Wilfredo y Manuel Valladares (1977), Los movimientos campesinos en el Perú, 1879-1965, Lima: Delva.

Mariátegui, José Carlos (1994), "La agitación revolucionaria y socialista del mundo oriental" [1923], en Mariátegui Total, tomo I, Lima: Empresa Editora Amauta, pp. 899-902.

Martínez Verdugo, Arnoldo (1985), Historia del Comunismo en México, México: Grijalbo.

Massardo, Jaime (2008), La formación del imaginario politico de Luis Emilio Recabarren: contribución al estudio crítico de la cultura politica de las clases subalternas de la sociedad chilena, Santiago: LOM.

Melgar Bao, Ricardo (2002), "Redes del exilio aprista en México (1923-1924), una aproximación", en Pablo Yankelevich (coord.), México, país de refugio. La experiencia de los exilios en el siglo XX, México: INAH-Plaza y Valdés, pp. 245-263.

- (2006-2007), "Un neobolivarianismo antiimperialista: La Unión Centro Sud Americana y de las Antillas (UCSAYA)", Politicas de la Memoria (Buenos Aires), no 6-7, verano, pp. 149-163.

- (2010), "Huellas, redes y prácticas del exilio intelectual aprista en Chile", Carlos Altamirano (dir.), Historia de los intelectuales en América Latina, tomo II, Buenos Aires: Katz, pp. 146-176.

- (2015), La prensa militante en América Latina y la Internacional Comunista, México: INAH.

Ortiz Peralta, Rina (2008), "Papeles mexicanos en Rusia", Diario de Campo (México), nº 99, julio-agosto, pp. 18-23.

Selser, Gregorio (2001), Cronología de las intervenciones extranjeras en América Latina, tomo III, México: UNAM-Universidad Obrera de México.

$* * *$

Título: "Between the Russian Revolution and Our America. Approach to the militant press, 1919-1935".

Resumen: La prensa militante cominternista no siguió el canon leninista de "organizador", afirmándose como medio de información y denuncia, y sobre todo, como modelador de su politicidad. Osciló entre ser abierta o cerrada, legal o clandestina, frentista o sectaria, doctrinaria o empirista. Su existencia fue accidentada: escasez de recursos y falta de infraestructura. En sus páginas se 
manifiestan sus fisuras internas y sus relevos editoriales, además de brindar indicios significativos acerca de su irradiación y de sus redes. Consideramos que la prensa militante es una fuente histórica de calidad de carácter complementario a la documental existente en archivos nacionales y extranjeros.

Palabras clave: Comintern - prensa militante - politicidad - edición - recepción

\begin{abstract}
The cominternist militant press did not follow the Leninist canon of "organizer", affirming himself as a means of information and denunciation, and above all, as a modeler of his politics. It oscillated between being open or closed, legal or clandestine, frenzied or sectarian, doctrinaire or empiricist. Their existence was uneven: scarcity of resources and lack of infrastructure. In its pages its internal fissures and its editorial relays are manifested, in addition to providing significant indications about its irradiation and its networks. We consider that the militant press is a historical source of quality of character complementary to the documentary existing in national and foreign archives.
\end{abstract}

Keywords: Comintern - militant press - politicity - editing - reception 